\title{
Utilisation of a community-based health facility in a low-income urban community in Ibadan, Nigeria
}

\author{
Authors: \\ Ayodeji M. Adebayo ${ }^{1}$ \\ Michael C. Asuzu ${ }^{1}$

\section{Affiliations:} \\ ${ }^{1}$ Department of Preventive \\ Medicine and Primary \\ Care, College of Medicine, \\ University of Ibadan, Ibadan \\ Correspondence to: \\ Ayodeji Adebayo \\ Email: \\ davidsonone@yahoo.com \\ Postal address: \\ PO Box 1517, UI Post Office, \\ Ibadan

\section{Dates:} \\ Received: 20 June 2014 \\ Accepted: 08 Oct. 2014 \\ Published: 05 May 2015 \\ How to cite this article: \\ Adebayo AM, Asuzu MC. \\ Utilisation of a community- \\ based health facility in a \\ low-income urban \\ community in Ibadan, \\ Nigeria. Afr J Prm Health Care \\ Fam Med. 2015;7(1), Art. \\ \#735, 8 pages. http://dx.doi. \\ org/10.4102/phcfm.v7i1.735

\section{Copyright:} \\ (C) 2015. The Authors. \\ Licensee: AOSIS \\ OpenJournals. This work is \\ licensed under the Creative \\ Commons Attribution \\ License.
}

\section{Read online:}

Scan this QR code with your smart phone or mobile device to read online.
Background: Primary healthcare is established to ensure that people have access to health services through facilities located in their community. However, utilisation of health facilities in Nigeria remains low in many communities.

Aim: To assess the utilisation of community-based health facility (CBHF) amongst adults in Ibadan, Nigeria

Settings: A low-income community in Ibadan North West Local Government Area of Oyo State.

Methods: A cross-sectional survey was conducted using a simple random sampling technique to select one adult per household in all 586 houses in the community. A semi-structured interviewer-administered questionnaire was used to collect information on respondents' sociodemographic characteristics, knowledge and utilisation of the CBHF. Data analysis included descriptive statistics and association testing using the Chi-square test at $p=0.05$

Results: The mean age of the respondents was $46.5 \pm 16.0$ years; $46.0 \%$ were men and $81.0 \%$ married; $26 \%$ had no formal education and $38.0 \%$ had secondary-level education and above; traders constituted $52.0 \%$ of the sample; and $85.2 \%$ were of low socioeconomic standing; $90 \%$ had patronised the CBHF. The main reasons for non-utilisation were preference for general hospitals (13.8\%) and self-medication (12.1\%). Respondents who had secondary education and above, were in a higher socioeconomic class, who had good knowledge of the facility and were satisfied with care, utilised the CBHF three months significantly more than their counterparts prior to the study $(p<0.05)$. However, only satisfaction with care was found to be a significant predictor of utilisation of the CBHF.

Conclusion: The utilisation of the CBHF amongst adults in the study setting is high, driven mostly by satisfaction with the care received previously. Self-medication, promoted by uncontrolled access to drugs through pharmacies and patent medicine stores, threatens this high utilisation.

Utilisation d'un établissement communautaire de santé dans un quartier urbain à faibles revenus d'Ibadan, Nigéria.

Contexte: Les soins de santé primaire ont été établis pour permettre aux gens d'avoir accès aux services de santé dans des établissements installés dans leur communauté. Cependant, l'utilisation des équipements sanitaires au Nigeria est faible dans de nombreuses communautés.

Objectif: Evaluer l'utilisation d'un établissement communautaire de santé (CBHF) par les adultes à Ibadan, Nigeria

Situation: Une communauté à faibles revenues dans la Zone de Gouvernement local d'Ibadan Nord Ouest (IBNWLGA) de l'état d'Oyo.

Méthodes: On a effectué une enquête transversale au moyen d'une technique d' échantillonnage simple au hasard pour sélectionner un adulte par ménage dans les 586 maisons de la communauté. On s'est servi d'un questionnaire semi-structuré administré par l'interviewer pour collecter les informations sur les caractéristiques sociodémographiques, les connaissances et l'utilisation du CBHF par les personnes interrogées. L'analyse des données comprenait des statistiques descriptives et des tests d'association au moyen du test de Chi-carré à $p=0.05$.

Résultats: L'âge moyen des personnes interrogées était de $46.5 \pm 16.0$ ans; $46.0 \%$ étaient des hommes et $81.0 \%$ étaient mariés. Vingt-six pour cent n'avaient pas d'éducation formelle; et 38.0\% avaient fait des études secondaires et plus. Les commerçants constituaient $52.0 \%$ de l'échantillon; et $85.2 \%$ avaient un statut socioéconomique modeste. Quatre-vingt-dix pour cent avaient fréquenté le CBHF. Les raisons principales pour la non utilisation de l'établissement étaient une préférence pour les hôpitaux généraux (13.8\%) et l'automédication (12.1\%). Les personnes interrogées qui avaient fait des études secondaires et plus, appartenaient à une classe sociale supérieure; ils connaissaient bien l'établissement et étaient satisfaits des soins, et ils avaient considérablement utilisé le CBHF trois mois avant l'enquête par rapport à leurs homologues $(p<0.05)$. Cependant, seule la satisfaction des soins était un indice significatif de l'utilisation du CBHF.

Conclusion: L'utilisation du CBHF par les adultes de l'étude est élevée, et liée essentiellement à la satisfaction des soins reçus au paravent. L'automédication, encouragée par l'accès incontrôlé aux médicaments des pharmacies et des magasins qui vendent des médicaments brevetés, menace l'utilisation élevée de l'établissement. 


\section{Introduction}

Primary healthcare $(\mathrm{PHC})$ is defined as:

essential healthcare based on practical, scientifically-sound and socially-acceptable methods and technology made universally accessible to individuals and families in the community by means acceptable to them at a cost that the community and country can afford to maintain at every stage of their development in a spirit of self-reliance and self-determination. ${ }^{1}$

It forms an integral part of both the countries' health system of which it is the central function and the main focus of the overall social and economic development of the community. It is also the first level of contact of individuals, families and communities with the national health system, bringing healthcare as close as possible to where people live and work and constitutes the first element of continuing health care process. ${ }^{1}$

Emphasis in healthcare has changed from healthcare for the people to healthcare by the people. Health is meant to be earned and maintained by the individuals. ${ }^{2}$ However, despite the fact that it is a fundamental human right, the community also has a role to play in contributing to the health of its members and the community as a whole. Apart from contributing toward the planning and implementation of planned programmes aimed at developing the community, the community also needs to utilise relevant health facilities in an appropriate manner.

The inception of PHC has facilitated some communities to have at least one health care facility sited as close as possible to where they live or work in all the districts or local government areas of many of the states in Nigeria. However, siting of health care facility does not necessarily translate to its utilisation; more so, that one of the major factors maintaining high mortality rate in Nigeria is poor access to and utilisation of health services. ${ }^{3,4}$ Several other factors, such as availability and cost of services, location of facility from clients/patients, competencies and attitudes of service providers, the peculiarity of patients' need and adequacy of resources can affect effective healthcare delivery. In a literature review of the situation of health-seeking behaviour in developing countries, by Shaikh and Hatcher in Pakistan, ${ }^{5}$ physical, socioeconomic, cultural and political contexts were documented as being the factors responsible for utilisation of a healthcare system, whether public or private, formal or informal. ${ }^{5}$ Details of these factors may include sociodemographics, social structures, educational status, gender discrimination, cultural beliefs and practices, employment status, women status, political will, the disease pattern, environmental conditions and healthcare system itself. $^{5}$

Primary healthcare is established to ensure that people have access to health services through health facilities located in their community. However, utilisation of health facilities in Nigeria remains unacceptably low in many communities. A household survey amongst 630 respondents in Northern
Nigeria showed that the majority preferred to use patent medicine stores $(53.63 \%)$ compared with only $7.6 \%$ who utilised the PHC services. ${ }^{6}$ In another study to assess the utilisation of PHC facilities in a rural community in southwestern Nigeria, $44 \%$ of the respondents who were ill in the three months preceding the survey had used the health facility. ${ }^{7}$ In many, if not all countries in Africa, as well as in other developing countries worldwide, most morbidities are treated at home and are never reported to the formal healthcare system. ${ }^{8}$ Clinical problems that present to the formal healthcare facilities are, therefore, only the tip of the iceberg. For example, for every case of febrile illness attended to in the formal healthcare facilities, approximately 4-5 more existed in the community in resource-poor countries. ${ }^{8}$

Studies on health services utilisation often seek to understand both the frequency and trends in the use of health services, as well as the possible mechanisms that may be associated with the pattern of use. ${ }^{9}$ Good knowledge and understanding of utilisation also help health providers and health systems managers to plan and improve on health services. However, it has been observed that such studies have been neglected, especially since the early 1990s. Given that most PHC facilities in Nigeria were established without an evaluation of their accessibility to the communities they are meant to serve, gaining an understanding of how people use health facilities cannot be over-emphasised. This is even more so in developing countries, including Nigeria, where people's knowledge of and attitude toward health services and the use of these services are still poor. ${ }^{4,10,11,12}$

\section{Aims and objectives}

Given that the utilisation of the CBHF by the community members at Idikan, Ibadan, Nigeria has hitherto not been assessed since its advent, the current study aimed to assess the utilisation of the facility within the three months preceding the study and to identify reasons for any lack of utilisation. It is hoped that the findings of this study will inform interventions for the improvement of PHC services in the community, hence the need for this study. Achieving this will enable better decisions to be made, which should result in better, more effective primary care for the people of the area in the long run. Therefore, the objective of this study was to assess the utilisation of the facility within the three months preceding the interview as well as to assess any reasons for any lack of utilisation of the facility, so that these can be corrected, if possible, for the improvement of PHC in the area.

\section{Research methods and design Study design}

This was a community-based descriptive cross-sectional survey.

\section{Research setting}

The study was conducted in Idikan, a low-income urban community located in Ibadan North West Local Government 
Area of Oyo State, South-western Nigeria. The community has an estimated population of 13902 based on the 2006 population census. ${ }^{13}$ The majority of the inhabitants are petty traders, artisans and farmers - the men are mostly artisans and farmers whilst the women are traders. Almost everybody in the community is from the Yoruba tribe - the dominant ethnic group in the south-western part of Nigeria. A great majority of the inhabitants have no formal education and belong to a low socioeconomic class. Idikan, as with other traditional areas of Ibadan, is grossly unplanned and has limited access to pipe-borne water and an irregular electricity supply. The CBHF was established in 1963 to serve the urban Idikan community. The programme was designed to promote health and to provide basic medical services to the community members as well as to provide an avenue for teaching urban community healthcare to the students of the Ibadan Medical School. With the advent of PHC in 1978, the service was expected to provide as much of all community/PHC services to the community as possible. The services are run from Monday to Friday for six hours per day by community health nurses and resident doctors, supervised by consultant community physicians from the Department of Community Medicine, University College Hospital, Ibadan. Two members of the community (community health assistance) provide assistance in the running of services at the facility. Currently, the clinic attends to an average 15-20 adults per day. There is a community health committee meant to ensure community participation in sustaining the services provided at this facility. The members of the committee contribute to the planning and implementation of programmes for their development through provision of funds, logistic and human resources; and in the utilisation of this facility.

\section{Study population}

The study population consisted of male and female adults residing in selected households.

\section{Sample size calculation}

The sample size was calculated using Leslie Kish's formula for descriptive surveys. ${ }^{14}$ A minimum sample size of 398 respondents was estimated, taking into consideration the prevalence of utilisation of health facilities of $44 \%$ from a previous study, ${ }^{15}$ with a critical ratio of 1.96 , a level of precision of $5 \%$ and a non-response rate of $5 \%$.

\section{Sampling methods}

There were a total of 586 houses in Idikan community with an average of 3-4 households per dwelling. All 586 houses were visited. In places where there were more than one household per house, one household was selected randomly by balloting. In the selected household, one adult was selected by a simple random sampling technique by balloting.

\section{Research instrument and data collection}

The study was conducted using a semi-structured intervieweradministered questionnaire. Five research assistants were recruited from the community and trained in order to administer the questionnaire. The interview was conducted mostly in the evening, which is when most of the community members were around. The questionnaire covered: sociodemographic characteristics; perception of community health services by adult members in the community; pattern of presentation in the three months preceding the interview; the utilisation of the CBHF for common illnesses in the three months preceding the interview; and obstacles against use of the community health services.

The questionnaire was standardised after it had been critiqued during a departmental proposal presentation with consultants, senior registrars and registrars present. Through constructive criticism, any possible shortcomings which could affect the quality and feasibility of the study were identified and rectified. The questionnaire was translated into Yoruba for the benefit of the majority who were predominantly Yoruba speaking, then translated back to formal English by a different translator from the first to ensure that there was no error in translation and that the original meaning was retained.

Pretesting was carried out on 15 subjects in Abebi, an adjoining community in the area which was not part of the study area but has similar characteristics. The pre-test was found necessary in order to ensure clarity of interpretation, ease of completion, reduce respondents' bias and generate useful questions not initially conceived but very germane to the quality of the study and to correct any ambiguity whatsoever detected. Corrections and relevant restructuring were made in places of ambiguity.

\section{Data collation and analysis}

The data obtained were sorted out, edited and manually cleaned and recoded where necessary. Data were entered into the computer and analysed with SPSS software v 16.0 (SPSS Inc., Chicago, IL 2007). Data analysis was done with the assistance of a statistician using both descriptive and inferential statistics. Descriptive statistics such as percentages or proportions were used to describe the qualitative or categorical variables. The Chi-square test was used to examine the relationship between two categorical variables. The test was carried out at 5\% level of significance.

Responses to questions on knowledge of the CBHF were converted to a 40-point score by coding a correct answer as ' 1 ' and a wrong answer as ' 0 '. The knowledge scores were generated giving minimum and maximum obtainable scores of 0 and 40 respectively. Respondents were categorised into having good, fair and poor knowledge using 75\% and above, $50 \%-74 \%$ and $49 \%$ and below of the maximum obtainable scores, respectively. Seventy-five per cent was used as the lowest limit for good knowledge because the CBHF had been in Idikan community for more than two decades before this assessment. It was located both centrally and within $1 \mathrm{~km}$ of all the community members for easy accessibility. Hence, respondents with a knowledge score of 30 and above 
were reported as having good knowledge, fair (20-29) and poor $(<20)$. Similarly, responses to perception questions were converted to a 60 -point score. Perception scores were generated with minimum and maximum obtainable scores of 12 and 60 respectively. Respondents were classified into having poor, fair and good perception of some characteristics of the CBHF using $75 \%$ and above, $50 \%-74 \%$ and $49 \%$ and below of the total obtainable scores, respectively. Hence, those with scores of 36 or less were regarded as having poor perception, 37-49 fair and $\geq 50$ good perception. Satisfaction with the services at the CBHF was assessed by asking if respondents were satisfied with the services received at the facility, generating a 'yes' or 'no' response.

Multivariate analysis using binary logistic regression ${ }^{16}$ was used to identify predictors of utilisation of the CBHF. The independent variables entered into the logistic regression model were those that were significant at $10 \%(p<0.1)$ on bivariate analysis.

The occupation of respondents was classified into high and low occupational class for ease of bivariate analysis, in some instances by modifying the social class based on occupation alone, as adopted from Rose and Pevalin (2001). ${ }^{17}$ Those classified as high occupational class were those in social class I and II (including professionals, senior civil servants and those in managerial occupations), whilst the low occupational class consisted of those in social class III, IV and V (including traders, artisans, farmers, drivers, etc.). Socioeconomic status was classified into high and low using the educational level and occupation of respondents. Those in the high occupational class with tertiary education were classified as the high socioeconomic class whilst those in the low occupational class with secondary education and below were classified as the low socioeconomic class.

\section{Ethical considerations}

Ethical approval was obtained from Oyo State Ethical Review Committee, State Ministry of Health (reference number AD/13/479/146). Permission and cooperation were sought from the High Chief of Idikan Community. Verbal informed consent was also ensured from all the participants. No names were recorded on the questionnaire so as to ensure confidentiality; and codes were used for identification of respondents instead of names.

\section{Results}

A total of 586 households were visited, from which 554 respondents consented - a response rate of $95 \%$. The respondents' sociodemographic characteristics are shown in Table 1 . The mean age was $46.5 \pm 16$ years with the highest proportion ( $n=237,42.6 \%)$ being in the $30-49$ year age group. Most were women $(n=300,54 \%)$ and from a monogamous family setting $(n=352,63.5 \%)$. Traders comprised $52.2 \%$ $(n=289)$ of the sample, $173(31.2 \%)$ had secondary education and $347(62.2 \%)$ were of the Islamic religion. Most of the respondents were married $(n=447,80.7 \%)$, of the Yoruba
TABLE 1: Sociodemographic characteristics of respondents.

\begin{tabular}{|c|c|c|}
\hline Variables $(N=554)$ & Frequency & Percentage \\
\hline \multicolumn{3}{|l|}{ Gender } \\
\hline Male & 254 & 46 \\
\hline Female & 300 & 54 \\
\hline \multicolumn{3}{|l|}{ Age group } \\
\hline$<20$ & 4 & 0.7 \\
\hline $20-29$ & 78 & 14.1 \\
\hline $30-39$ & 121 & 21.8 \\
\hline $40-49$ & 116 & 20.8 \\
\hline $50-59$ & 87 & 15.7 \\
\hline $60-69$ & 74 & 13.4 \\
\hline$>70$ & 57 & 10.3 \\
\hline No response & 17 & 3.1 \\
\hline \multicolumn{3}{|l|}{ Ethnicity } \\
\hline Yoruba & 507 & 91.5 \\
\hline Igbo & 43 & 7.8 \\
\hline Hausa & 4 & 0.7 \\
\hline \multicolumn{3}{|l|}{ Marital status } \\
\hline Single & 29 & 5.2 \\
\hline Married & 447 & 80.7 \\
\hline Separated & 13 & 2.3 \\
\hline Divorced & 13 & 2.3 \\
\hline Widowed & 52 & 9.4 \\
\hline \multicolumn{3}{|l|}{ Religion } \\
\hline Islam & 347 & 62.6 \\
\hline Christianity & 205 & 37 \\
\hline Traditional & 2 & 0.4 \\
\hline \multicolumn{3}{|l|}{ Type of marriage } \\
\hline Monogamous & 352 & 63.5 \\
\hline Polygamous & 202 & 36.5 \\
\hline \multicolumn{3}{|l|}{ Level of education } \\
\hline No formal education & 143 & 25.8 \\
\hline Quranic & 49 & 8.8 \\
\hline Primary & 153 & 27.6 \\
\hline Secondary & 173 & 31.2 \\
\hline Tertiary & 36 & 6.5 \\
\hline \multicolumn{3}{|l|}{ Occupation } \\
\hline Professional $\dagger$ & 24 & 4.3 \\
\hline Civil servant & 25 & 4.5 \\
\hline Artisan & 90 & 16.2 \\
\hline Trading & 289 & 52.2 \\
\hline Unemployed & 56 & 10.1 \\
\hline Other: & 70 & 12.6 \\
\hline \multicolumn{3}{|c|}{ Monthly income[Naira] } \\
\hline$<5000$ & 241 & 43.5 \\
\hline 5000-9999 & 79 & 14.3 \\
\hline$>10000$ & 124 & 22.3 \\
\hline No response & 110 & 19.9 \\
\hline \multicolumn{3}{|l|}{ Socioeconomic status } \\
\hline Low $(1-5)$ & 472 & 85.2 \\
\hline High (6-9) & 82 & 14.8 \\
\hline \multicolumn{3}{|c|}{ Distance of respondents house from health facility } \\
\hline$\leq 5 \mathrm{~km}$ & 434 & 78.3 \\
\hline$>5 \mathrm{~km}$ & 120 & 21.7 \\
\hline
\end{tabular}

$\dagger$, Engineers, teachers; $\$$, Clergy, students, drivers, farmers.

tribe ( $n=507,91.5 \%)$ and within the low socioeconomic status $(n=472,85.2 \%)$.

The majority ( $n=484,82.5 \%$ ) of the respondents felt that the best place to seek help when sick is the CBHF. Regarding the service components of PHC available at the CBHF, 211 
(42.5\%) knew about health education and 183 (36.9\%) were aware of referral services. This was followed by knowledge of antenatal services $(n=169,34.1 \%)$ and immunisation ( $n=118,23.8 \%$ ). Questions were asked to test the respondents' knowledge about some of the characteristics of the services provided at the CBHF, for example: if they were provided free; rendered 24 hours daily; availability of a community health committee; and if members of the community are part of the working staff. In each of the first three knowledge questions, well above 50\% $(n=336,67.7 \% ; n=361,72.8 \%$; and $n=310,62.5 \%$, respectively) answered correctly, except for the last question (if members of the community are part of the working staff), where only $47.6 \%$ were correct. Just over half of the respondents ( $n=284,57.3 \%$ ) had good knowledge of the administrative structure and functions of the CBHF as well as the services there (Table 2).

Most the respondents ( $n=496,89.5 \%$ ) had patronised the CBHF. Of the 554 respondents, 369 (76.1\%) reported that they were satisfied with the care received at the CBHF. Amongst those that had ever received treatment in the facility, the perceived reasons for seeking care include good services $(89.5 \%)$, nearness to the house $(84.1 \%)$, prompt attention $(69.2 \%)$ and available of essential drugs (68.5\%) (Figure 1). Amongst those that had never utilised the CBHF, 21 (36.2\%)

TABLE 2: Distribution of respondents regarding knowledge of the communitybased health facility.

\begin{tabular}{lcc}
\hline Knowledge areas ( $N=496)$ & Correct $\boldsymbol{n}(\%)$ & Incorrect $\boldsymbol{n}$ (\%) \\
\hline Owner of the facility & $373(75.2)$ & $123(24.8)$ \\
Types of services provided & & \\
Antenatal care & $327(65.9)$ & $169(34.1)$ \\
Immunisation & $378(68.2)$ & $118(23.8)$ \\
Family planning & $454(91.5)$ & $42(8.5)$ \\
Treatment of common ailments & $389(78.4)$ & $107(21.6)$ \\
Health education & $285(57.5)$ & $211(42.5)$ \\
Referral & $313(61.3)$ & $183(36.9)$ \\
Ultra Sound Scan & $298(60.1)$ & $198(39.9)$ \\
Characteristics of services provided & $336(67.7)$ & $160(32.3)$ \\
Free & $361(72.8)$ & $135(27.2)$ \\
24 hours & $310(62.5)$ & $186(37.5)$ \\
Availability of community health committee & $236(47.6)$ & $260(52.4)$ \\
Members of the community provide assistance & & \\
at the facility & & \\
Overall knowledge rating regarding the community-based health facility \\
Good (30 and above) & 284 & 57.3 \\
Fair (20-29) & 116 & 23.4 \\
Poor (19 and below) & 96 & 19.3 \\
\hline
\end{tabular}

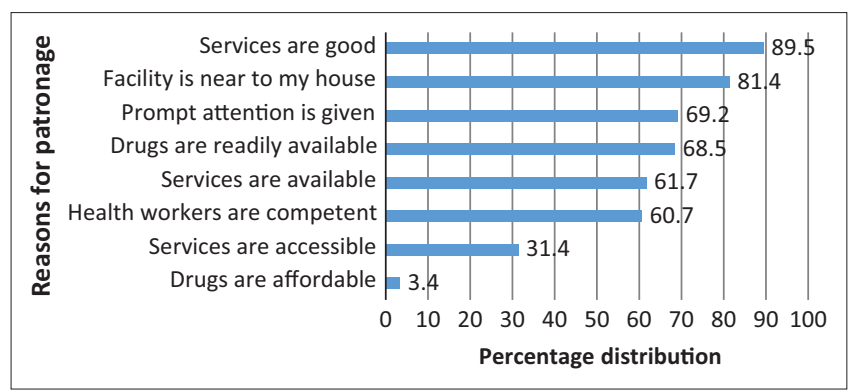

FIGURE 1: Percentage distribution of respondents by reasons for utilising the community-based health facility. proffered reasons for non-patronage as preference for general hospital (13.8\%), self-medication (12.1\%) and one person $(1.7 \%)$ reported a preference for traditional practitioners.

Amongst those that sought medical care outside the home in the three months preceding the interview, 212 (93.8\%) specified their sources of care. One hundred and fifty-one respondents $(66.8 \%)$ reported the $\mathrm{CBHF}$ as their source of medical care three months prior to interview, $34(15.0 \%)$ a private hospital, 16 (7.1\%) government-owned hospitals and $11(4.9 \%)$ a faith-based organisation.

Results of the bivariate analysis are shown in Table 3, indicating that the higher occupational class $(p=0.013)$, higher socioeconomic class $(p=0.01)$, having secondary education and above $(p=0.023)$, being unmarried ( $p=0.002)$, satisfaction with previous care $(p<0.001)$ and having good attitude, perceptions and knowledge $(p<0.001)$ were all associated with having received treatment from the CBHF in the preceding three months.

In the multivariate logistic regression analysis (Table 4), only satisfaction with care received was a significant predictor of utilisation of services at the CBHF. Respondents that were not satisfied with care were less likely $(\mathrm{OR}=0.378$; 95\% $\mathrm{CI}=0.144-0.994 ; p=0.049)$ to use the CBHF.

\section{Discussion}

This study was carried out to assess the utilisation of the CBHF by adult members in a low-income urban community in Ibadan for the purpose of promoting/optimising and upgrading $\mathrm{PHC}$ in the area. The majority of the respondents $(89.5 \%)$ had utilised the CBHF at one time or the other and utilisation of services in the preceding three months was equally high (89\%). Utilisation in the preceding three months was in relation to treatment of injuries and ailments, whether acute or chronic. However, the respondents' awareness of the service components of PHC provided at the CBHF was low. Less than half knew about health education, $36.9 \%$ were aware of referral services, followed by antenatal services (34.1\%) and immunisation (23.8\%). This means that respondents were not aware of the full range of the services provided at the CBHF based on the PHC service components. Utilisation of services in the preceding three months showed that they were more familiar with use of the facility for treatment of disease conditions such as malaria, hypertension and diabetes. The low awareness of the service components of PHC amongst respondents in this study may be a result of poor enlightenment of the public regarding the component services available at the centre with health workers, provision of services for only six hours without admission; non-provision of delivery services, in addition to antenatal care, which would have encouraged patients and relatives to stay for a longer period in the facility and provide opportunities for exposure to the other services being offered at the centre. The poor awareness reported in our study is in contrast to a community-based study in India where awareness of services was high but utilisation was relatively 
TABLE 3: Association between utilisation of services at the community-based health facility for three months before survey and respondents' characteristics.

\begin{tabular}{|c|c|c|c|c|}
\hline \multirow[t]{2}{*}{ Variables } & \multicolumn{2}{|c|}{ Received treatment in last 3 months } & \multirow[t]{2}{*}{$X^{2}$} & \multirow[t]{2}{*}{$p$-value } \\
\hline & Yes $n(\%)$ & No $n(\%)$ & & \\
\hline \multicolumn{5}{|l|}{ Age group (yrs) } \\
\hline$<30$ & $21(25.6)$ & $61(74.4)$ & \multirow{3}{*}{3.938} & \multirow{3}{*}{0.140} \\
\hline $30-59$ & $96(29.6)$ & $228(70.4)$ & & \\
\hline 60 and above & $27(20.6)$ & $104(79.4)$ & & \\
\hline \multicolumn{5}{|l|}{ Gender } \\
\hline Male & $72(28.2)$ & $183(71.8)$ & \multirow{2}{*}{0.228} & \multirow{2}{*}{0.633} \\
\hline Female & $79(26.4)$ & $220(73.6)$ & & \\
\hline \multicolumn{5}{|l|}{ Occupational class } \\
\hline High & $18(43.9)$ & $23(56.1)$ & \multirow{2}{*}{6.188} & \multirow{2}{*}{$0.013^{*}$} \\
\hline Low & $133(25.9)$ & $380(74.1)$ & & \\
\hline \multicolumn{5}{|l|}{ Educational level } \\
\hline No formal & $41(21.4)$ & $151(78.6)$ & \multirow{3}{*}{7.569} & \multirow{3}{*}{$0.023^{*}$} \\
\hline Primary & $40(26.1)$ & $113(73.9)$ & & \\
\hline Secondary and above & $70(33.5)$ & $139(66.5)$ & & \\
\hline Socioeconomic status & & & & \\
\hline Low & $119(25.2)$ & $353(74.8)$ & 6772 & ค010* \\
\hline High & $32(39.0)$ & $50(61.0)$ & 0.122 & 0.010 \\
\hline Occupation of head of & household & & & \\
\hline Professional & $13(43.3)$ & $17(56.7)$ & & \\
\hline Civil servant & $9(28.1)$ & $23(71.9)$ & & \\
\hline Artisan & $24(23.3)$ & $79(76.7)$ & 5.130 & 0.275 \\
\hline Traders & $69(28.0)$ & $177(72.0)$ & & \\
\hline Other & $36(25.2)$ & $107(74.8)$ & & \\
\hline Marital status & & & & \\
\hline Never & $15(51.7)$ & $14(48.3)$ & & ? \\
\hline Ever & $136(25.9)$ & $389(74.1)$ & 9.24 & 0.002 \\
\hline Ethnicity & & & & \\
\hline Yoruba & $139(27.4)$ & $368(72.6)$ & & 781 \\
\hline Other & $12(25.5)$ & $35(74.5)$ & 0.017 & 0.101 \\
\hline Religion & & & & \\
\hline Christianity & $62(30.2)$ & $143(69.8)$ & 1465 & 62026 \\
\hline Islam & $89(25.5)$ & $260(74.5)$ & 1.405 & $0.2<0$ \\
\hline Family type & & & & \\
\hline Polygamous & $92(26.1)$ & 260 (73.9) & 0611 & 0435 \\
\hline Monogamous & $59(29.2)$ & $143(70.8)$ & 0.011 & 0.435 \\
\hline Household income & & & & \\
\hline$<5000$ & $71(31.4)$ & $157(68.6)$ & & \\
\hline 5000-9000 & $23(25.3)$ & $68(74.7)$ & 1.424 & 0.491 \\
\hline 10000 and above & $34(27.4)$ & 90 (72.6) & & \\
\hline Satisfaction & & & & \\
\hline Yes & 136 (36.9) & $233(63.1)$ & 37948 & $<0001 *$ \\
\hline No & $8(6.9)$ & $108(93.1)$ & $3 / .948$ & $<0.001 *$ \\
\hline Distance & & & & \\
\hline$\leq 5$ & $113(26.0)$ & $321(74.0)$ & 1502 & ח2 0 \\
\hline$>5$ & $38(31.7)$ & $82(68.3)$ & 1.503 & $0 . \angle 20$ \\
\hline No of days sickness la & & & & \\
\hline$\leq 14$ days & $136(30.8)$ & $306(69.2)$ & 1 & 098? \\
\hline$>14$ days & $15(30.6)$ & $34(69.4)$ & 0.001 & 0.982 \\
\hline Severity & & & & \\
\hline Mild & $104(31.1)$ & 230 (68.9) & $0 \cap 33$ & 0856 \\
\hline Severe & $47(30.3)$ & $108(69.7)$ & 0.033 & 0.856 \\
\hline Knowledge & & & & \\
\hline Poor $(<20)$ & $6(6.3)$ & $90(93.8)$ & & \\
\hline Fair (21-29) & $26(22.4)$ & $90(77.6)$ & 43.269 & $<0.001^{*}$ \\
\hline Good (30 and above) & $114(40.1)$ & $170(59.9)$ & & \\
\hline Perception & & & & \\
\hline Poor & $5(5.3)$ & $90(94.7)$ & & \\
\hline Fair & $12(40.0)$ & $18(60.0)$ & 33.421 & $<0.001^{*}$ \\
\hline Good & $129(34.8)$ & $242(65.2)$ & & \\
\hline
\end{tabular}

${ }^{*} p$-values $<0.05$
TABLE 4: Adjusted odds ratio of predictors of utilisation of the community-based health facility.

\begin{tabular}{|c|c|c|c|}
\hline Variables & Odds ratio & $95 \% \mathrm{Cl}$ & $p$-value \\
\hline \multicolumn{4}{|c|}{ Occupational class } \\
\hline High & 1.000 & & \\
\hline Low & 0.594 & $0.203-1.737$ & 0.342 \\
\hline \multicolumn{4}{|c|}{ Level of education } \\
\hline No formal & 1.000 & & \\
\hline Primary & 0.904 & $0.520-1.571$ & 0.719 \\
\hline Secondary & 0.913 & $0.514-1.621$ & 0.756 \\
\hline \multicolumn{4}{|c|}{ Socioeconomic status } \\
\hline Low & 1.000 & & \\
\hline High & 1.437 & $0.615-3.353$ & 0.402 \\
\hline \multicolumn{4}{|c|}{ Marital status } \\
\hline Never & 1.000 & & \\
\hline Ever & 0.409 & $0.138-1.213$ & 0.107 \\
\hline \multicolumn{4}{|l|}{ Satisfaction } \\
\hline Yes & 1.000 & & \\
\hline No & 0.378 & $0.144-0.984$ & $0.049 *$ \\
\hline \multicolumn{4}{|l|}{ Knowledge } \\
\hline Poor & 1.000 & & \\
\hline Fair & 0.831 & $0.132-5.249$ & 0.844 \\
\hline Good & 1.711 & $0.276-10.618$ & 0.564 \\
\hline \multicolumn{4}{|l|}{ Perception } \\
\hline Poor & 1.000 & & \\
\hline Fair & 4.278 & $0.495-36.982$ & 0.187 \\
\hline Good & 3.326 & $0.448-24.682$ & 0.240 \\
\hline
\end{tabular}

*p -value $<0.05$

low $(54.9 \%){ }^{12}$ Whilst our study assessed the various service components of PHC, the Indian study only inquired whether respondents were aware of the availability of PHC without exploring awareness of the various service components on offer. The relatively low awareness of the various services available at the CBHF, as documented by this study, will cause under-utilisation of the available services. Efforts at creating awareness of the available component services of PHC and promoting community mobilisation with the support of the community members will further benefit the community members by enhancing their use of the available promotive and preventive services at this facility.

The reasons adduced for utilisation of the CBHF were that services were good and readily available, health facility was nearer to their homes, drugs were readily available and attention was prompt. Reasons for non-utilisation in this study included preference for general hospitals, selfmedication, private hospitals and traditional healers. In a study to determine utilisation of approved health facilities for delivery in Ile-Ife, the reasons given for non-utilisation of the health facilities at hand were time of onset of labour, problems with transport, fear of surgery, husband and/or family influence and the fact that delivery was assisted by Traditional Birth Attendants (TBAs) and relatives. ${ }^{15}$ Even though our study assessed services in relation to various service components of PHC compared with the Ile-Ife study, which was specifically in facilities for delivery services, the different hours of service are not comparable: six hours in our facility as opposed to 24 hours in Ile-Ife. Reasons for nonutilisation in India were 'faith in quacks, inconvenient timing of the primary health centre, long queues, non-availability 
of drugs, and investigations' ${ }^{12}$ Interventions to address these factors will improve the current utilisation rate.

The practice of self-medication amongst $12.1 \%$ of the respondents is worthy of mention. Considering the fact less than a third reported that the services at the CBHF were not readily accessible may be explained by the fact that services are only accessible in this facility for a maximum of six hours per day. This may force community members to become more dependent on self-medication and traditional healers because drugs are not available at all hours. This automatically makes the services of 'quacks' and patent medicine merchants readily available. However, there is also the possibility that their low level of education and strong cultural beliefs could contribute equally to this. However, a survey in Kathmandu, Nepal, showed that individuals turned to modern health sector 'because they are dissatisfied with the previous folk or traditional professional consultation or because or traditional practitioners had advised them to seek modern hospital services'.18 Another study in South Africa on community knowledge and perception of malaria reported that $66.9 \%$ of the respondents would seek treatment at the hospital when symptoms are severe. ${ }^{19}$ From a study conducted in the former Soviet Union on health service utilisation, the main reason for not seeking care was lack of funds to pay for treatment $(42.5 \%)$, self-treatment with home remedies $(32.9 \%)$ and purchase of non-prescription medication. ${ }^{20}$ An extension of the hours of services at the CBHF may reduce clients' exposure to use of self-medication and traditional healers. This will prevent the clinical and policy implications of buying over-the-canter drugs which may generate drug resistance, increased morbidity and mortality through incompletely-treated cases, use of wrong medication, sub-normal doses and the adverse effects of drugs and herbal medications.

The findings of this research on bivariate analysis indicated that utilisation patterns can be explained, to a large extent, by factors relating to occupational class, socioeconomic status, level of education and level of satisfaction, as well as knowledge of and perception of respondents toward the services. However, it was only the level of satisfaction that was a significant predictor on logistic regression. These findings are consistent with findings from prior research: a bivariate analysis in determinants of utilisation of health services in the western states of Nigeria revealed age, level of education, type of education, place of work and attitudes toward services as being significant factors. ${ }^{21}$ A similar study in the determinants of maternal services in a rural Nigeria city showed that the mother's education and occupation of, as well as the husband's religion and occupation were associated significantly with delivery at a health facility on logistic regression analysis. This study showed a higher likelihood of utilisation of health services amongst postprimary education mothers than those with no occupation; and in Christian mothers versus their counterparts. ${ }^{22}$ "The woman's educational level and total number of living children were the most significant predictors of prenatal care utilization' in Vietman. ${ }^{23}$ In another study on utilisation of an approved health facility for delivery in Ile-Ife, south west Nigeria, 'educational status of the mother, religious beliefs, distance from approved health facilities more than $5 \mathrm{~km}$ and attitude of health workers were amongst the factors significantly influencing choice of place of delivery' by the mother. ${ }^{15}$ This shows that promoting most of these factors through female education and positive attitudes of health workers toward work will further enhance the patronage of the CBHF. The results from both bivariate and multivariate analyses confirmed the importance of a mother's education in explaining the utilisation of maternal health services in a study to determine the use of such services in rural Bangladesh. The Bangladesh study also reported the significant effect of severity of disease condition in predicting the utilisation of maternal health care. Multivariate analysis indicated that women having had a life-threatening condition were more likely to seek care from a health facility. ${ }^{24}$

'The distance patients must travel in order to obtain treatment has long been recognized as a primary determinant of the utilization of health care facilities' ${ }^{\prime 25}$ However, it was not found to be a significant factor in this study, contrary to the findings of Esimai et al. ${ }^{15}$ and Chakraborty et al. ${ }^{24}$ The distance is especially significant in:

[the] Third World settings where the density of Western type health facilities is often low, where the majority of patients are likely to make the journey for treatment as pedestrians and where there are viable and usually more accessible alternate sources of medicine..$^{25}$

\section{Conclusion}

The utilisation of the CBHF at Idikan was high but the awareness of the various service components of PHC was low. Higher occupational and socioeconomic status, higher level of education, satisfaction with previous care, good awareness and perception of the $\mathrm{CBHF}$ were factors associated with utilisation of CBHF, although only satisfaction with previous care predicted utilisation on logistic regression.

\section{Implications or recommendations}

Information on healthcare utilisation has important policy implications in health systems development. Public awareness programmes that mobilise the community to participate in the design and running of the CBHF need to be developed in order to increase awareness and sustain utilisation of the services at the CBHF. Issues surrounding waiting time, availability of drugs and accessibility should also be addressed by the institution in order to sustain the current level of utilisation. The stakeholders should review the hours of service from the current maximum of six hours to 24 hours; this might require scaling up of resources.

\section{Acknowledgements}

The authors would like to acknowledge the contributions of the research assistants, data entry clerk and analyst, the 
nursing officers at the community-based health facility and the community leaders and members for their cooperation and support.

\section{Competing interests}

The authors declare that they have no financial or personal relationship(s) that may have inappropriately influenced them in writing this article.

\section{Authors' contributions}

A.M.A. (University of Ibadan) was responsible for the conceptualisation of the study, supervision of the process of data collection, entry and analysis; and the writing of the manuscript. M.C.A. (University of Ibadan) was involved in the conceptualisation and supervision of the manuscript writing.

\section{References}

1. Lucas AO, Gilles HM. Organization of health services. In: Short textbook of public health medicine for the tropics. 4th ed. London: Arnold Publishers, 2003; p. 303.

2. Singh AR, Singh SA. The goal: Health for all. The commitment: All for health. Mens Sana Monogr. 2004; 2(1):97-110.

3. Mojekwu JN, Ibekwe U. Maternal mortality in Nigeria: Examination of intervention methods. International Journal of Humanities and Social Science 2012;2(20):135-149.

4. OlayinkaOA, Achi OS, Amos AO, et al. Awareness and barriers to utilization of maternal health care services among reproductive women in Amassoma community, Bayelsa State. Int J Nurs Midwifery. 2014 6(1):10-15. http://dx.doi. org/10.5897/IJNM2013.0108

5. Shaikh BT, Hatcher J. Health seeking behavior and health service utilisation in Pakistan: Challenging the policy makers. J Public Health (Oxf). 2004;27(1):49-54. http://dx.doi.org/10.1093/pubmed/fdh207

6. Muhammed KA, Umeh KN, Nasir SM, et al. Understanding the barriers to the utilization of primary health care in a low-income setting: implications for health policy and planning. J Public Health Africa. 2013;4(2);64-67. http://dx.doi. org/10.4081/jphia.2013.e13

7. Sule SS, ljadunola KT, Onayade AA, et al. Utilization of primary health care facilities: Lessons from a rural community in southwest Nigeria. Niger J Med. 2008;17(1):98-106. http://dx.doi.org/10.4314/njm.v17i1.37366
8. Agyepong IA, Kangeya-Kayonda J. Providing practical estimates of malaria burden for health planners in resource-poor countries. Am J Trop Med Hyg. 2004;71 (2 Suppl):162-167.

9. Habib OS, Vaughan JP. The determinants of health services utilization in Southern Iraq: A household interview survey. Int J Epidemiol. 1986;15(3):395-403. http://dx.doi.org/10.1093/ije/15.3.395

10. Streefland $\mathrm{PH}$. Public doubts about vaccination safety and resistance against vaccination. Health Policy. 2001;55(3):159-172. http://dx.doi.org/10.1016/ S0168-8510(00)00132-9

11. Houweling TA, Ronsmans C, Campbell OM, et al. Huge poor-rich inequalities in maternity care: An international comparative study of maternity and child care in developing countries. Bull World Health Organ. 2007;85(10): 745-754. http://dx.doi.org/10.2471/BLT.06.038588

12. Chandwani $H$, Jivajarani $P$, Jivarajani $H$. Community perception and client satisfaction about the primary health care services in a tribal setting of Gujarat India. The Internet Journal of Health. 2009;9(2):7.

13. National Population Commission (NPC). Nigerian population facts and figures [page on the Internet]. No date [cited 2014 Mar 16]. Accessed from: http://www. population.gov.ng/factsandfigures.htm [URL no longer valid]

14. Abbo C, Ekblad S, Waako W, et al. The prevalence and severity of mental illnesses handled by traditional healers in two districts in Uganda. Afr Health Sci. 2009;9(Suppl 1):S16-S22.

15. Esimai OA, Ojo OS, Fasubaa OB. Utilization of approved health facilities for delivery in Ile-Ife, Osun State, Nigeria. Nig J Med. 2002;11(4):177-179.

16. Allison PD. Multiple regression: A primer. Thousand Oaks, CA: Pine Forge Press; 1999.

17. Rose D, Pevalin DJ. The national statistics socio-economic classification: Unifying official and sociological approaches to the conceptualisation and measurement of social class. ISER working paper 2001-4. Institute for Social and Economic Research, University of Essex, Colchester.

18. Subedi J. Modern health services and health care behaviour: A survey in Kathmandu, Nepal. J Health Soc Behav. 1989;30(4):412-420. http://dx.doi. org/10.2307/2136989

19. Govere J, Durrheim D, La Grange K, et al. Community knowledge and perception about malaria and practices influencing malaria control in Mpumalanga province, South Africa. S Afr Med J. 2000;90(6):611-616.

20. Balabanova D, McKee M, Pomerleau J, et al. Health service utilisation in the former Soviet Union: Evidence from eight countries. Health Serv Res. 2004:39/6 pt 2):1927-1950. http://dx.doi.org/10.1111/j.1475-6773.2004.00326.x

21. Ademuwagun ZA. Determinants of pattern and degree of utilization of health services in Western State, Nigeria. Isr J Med Sci. 1997;13(9):896-907.

22. Nwakoby BN. Use of obstetric services in rural Nigeria. J R Soc Health 1994;114(3):132-136. http://dx.doi.org/10.1177/146642409411400304

23. Swenson IE, Thang NM, Nhan VQ, et al. Factors related to the utilization of prenatal care in Vietnam. J Trop Med Hyg. 1993;96(2):76-85.

24. Chakraborty N, Islam MA, Chowdhury RI, et al. Determinants of the use of maternal health services in rural Bangladesh. Health Promot Int. 2003;18(4): 327-337. http://dx.doi.org/10.1093/heapro/dag414

25. Stock R. Distance and the utilization of health facilities in rural Nigeria. Soc Sci Med. 1983;17(9):563-570. http://dx.doi.org/10.1016/0277-9536(83)90298-8 